\title{
Rarest of the Rare: Esthesioneuroblastoma in a Young Male
}

\author{
Akash Patel ${ }^{1}$, Bansi Adroja ${ }^{2}$, Hemant Joshi ${ }^{3}$, (COL) V. P. Singh ${ }^{4}$ \\ 1,2 Junior Resident, Department of General Medicine, SBKS Medical College and Research Institute, Pipariya, Vadodara, Gujarat \\ ${ }^{3}$ Senior Resident, Department of Neurology, SBKS Medical College and Research Institute, Pipariya, Vadodara, Gujarat
}

${ }^{4}$ Professor and Head of Unit, Department of General Medicine, SBKS Medical College and Research Institute, Pipariya, Vadodara, Gujarat

\begin{abstract}
Esthesioneuroblastoma is a rare tumor arising from the olfactory epithelium of the nasal vault which frequently invades the cranial base and orbit. Esthesioneuroblastoma has a bimodal age distribution between 11 and 20 years and between 51 and 60 years. Esthesioneuroblastoma accounts for approximately 1-5\% of intranasal cancers. Case reports published worldwide have been very few. Common presenting symptoms of Esthesioneuroblastoma include nasal obstruction, epistaxis, facial pain, diplopia, proptosis, and anosmia. Apart from being locally aggressive, it metastasizes widely by both hematogenous and lymphatic routes. The case is reported of a 22-year-old male patient with a Kadish stage C tumor with 3 months history of headache, nasal obstruction, anosmia, blurring of vision and epistaxis.
\end{abstract}

Keywords: Esthesioneuroblastoma, Olfactory neuroblastoma, malignant tumor of nasal cavity

\section{Introduction}

The incidence of Esthesioneuroblastoma is relatively low worldwide. A 1997 literature search identified 1,457 cases in the published literature [1]. The tumor was first described by Berger and Luc [2]. This tumor constitutes $3 \%$ of all intranasal neoplasm and can be seen in all ages, with a peak in the second and sixth decades of life and with equal distribution between the sexes $[\underline{1}, \underline{3}]$. The tumor aggressively spreads submucosally to involve the orbits, anterior cranial fossa, and brain. The most common site of metastasis is the cervical lymph nodes $(10-33 \%$ of patients), while sites of distant metastasis are the lungs, brain, and bone, but are less common $[\underline{1}, \underline{3}]$.

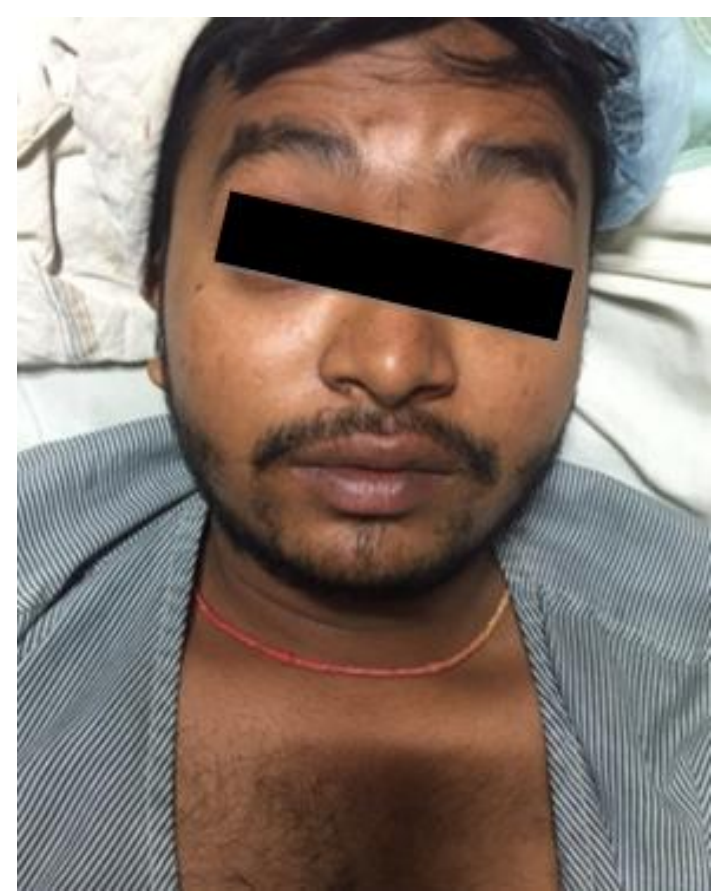

Figure 1

\section{Case Presentation}

22 year old male Hareshbhai Vasava presented to medicine department, Dhiraj General Hospital, piparia-waghodia, vadodara with chief complains of Headache for 3 months which was throbbing in nature, in frontal region and not responding to pain killer. After that he had developed complain of double vision and pain at eyes left more than right. He also had complain of nasal obstruction in both the nasal cavity which was sometimes associated with difficulty in taking breath from nostrils and intermittently episodes of epistaxis.

At presentation patient was conscious and well oriented and vitals were, Pulse- 100/minute, BP- 128/78 $\mathrm{mmHg}$, Respiratory rate-21/minute, $\mathrm{O}_{2}$ saturation $\left(\mathrm{SpO}_{2}\right)$ was $98 \%$ on room air on admission. On examination, thick blood stained foul smelling discharge was seen coming out of the nasal cavity which on cleaning revealed pinkish grey mass filling the both nasal cavity. The mass bled on manipulation. There was drooping of left eye lid. On central nervous system examination, there was bilateral involvement of cranial nerve I, II, III, IV and VI with signs of upper motor neuron disease in view of hyperreflaxia and hypertonia in all four limbs with bilateral extensor planters. Other systemic examination was normal.

Hematological and biochemical investigations were within normal range. Radiological investigations: MRI brain(plain + contrast) was seen of, A lobulated solid abnormal signal intensity mass lesion measuring $6.5(\mathrm{CC}) \times 5.5(\mathrm{~T}) \times 6.7(\mathrm{AP})$ $\mathrm{cm}$. noted involving both nasal cavity and ethmoid sinuses, lesion appears heterogeneously isointense to grey matter on $\mathrm{T} 2 \mathrm{~W}$ images and mild hypointense on T1W images. Lesion causes erosion of medial wall of both orbits and extending into extrachoanal compartment. Lesion in both orbits medially abuts bilateral superior and inferior recti muscle. Lesion causes erosion and distruction of ethmoid sinus walls. It causes destruction of floor of anterior cranial fossa 


\section{International Journal of Science and Research (IJSR) \\ ISSN (Online): 2319-7064 \\ Index Copernicus Value (2015): 78.96 | Impact Factor (2015): 6.391}

and extra axial space of anterior cranial fossa. Lesion both optic nerves(left>right). Above findings suggestive of infiltrates body of sphenoid and sphenoid sinus. Lesion infiltrates bilateral optic foramina causing compression of possibility of Esthesioneuroblastoma.

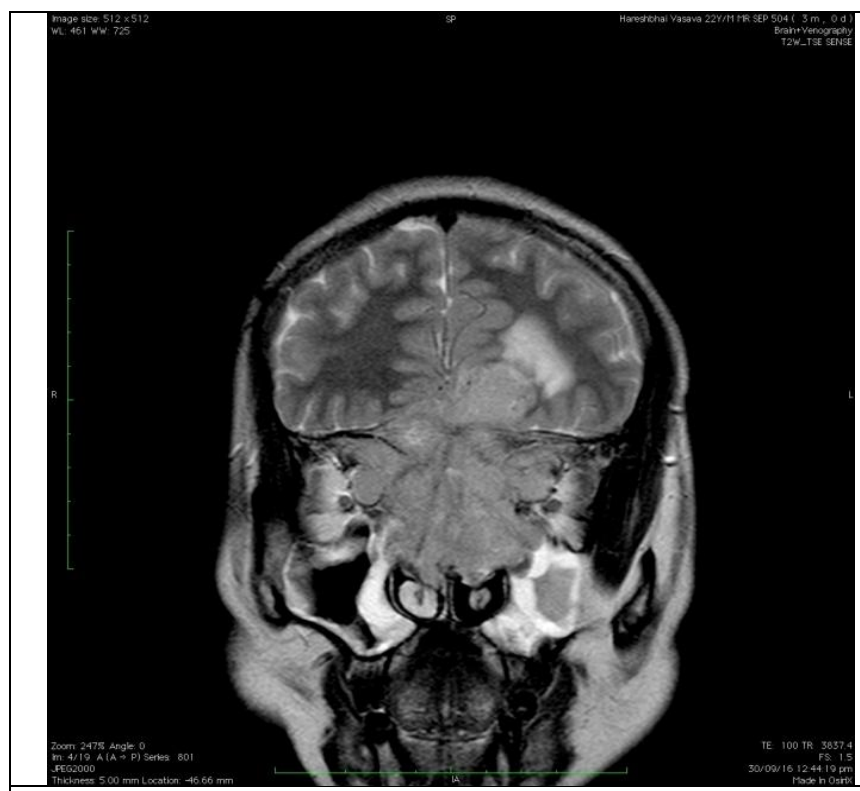

Figure 2

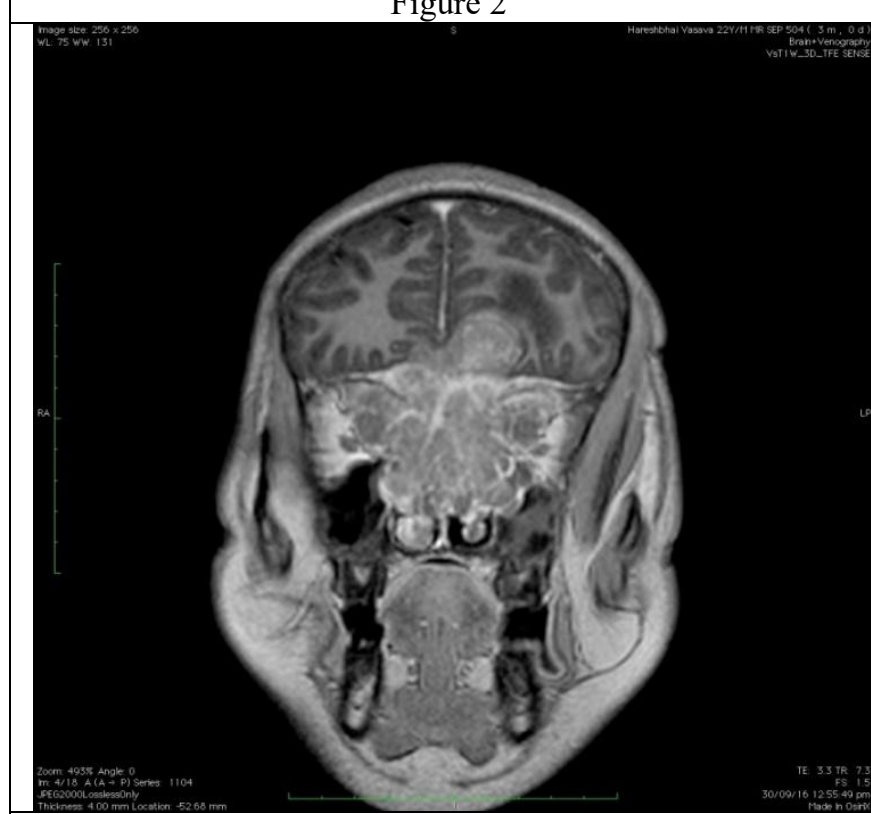

Figure 4(Post Contrast enhancement)

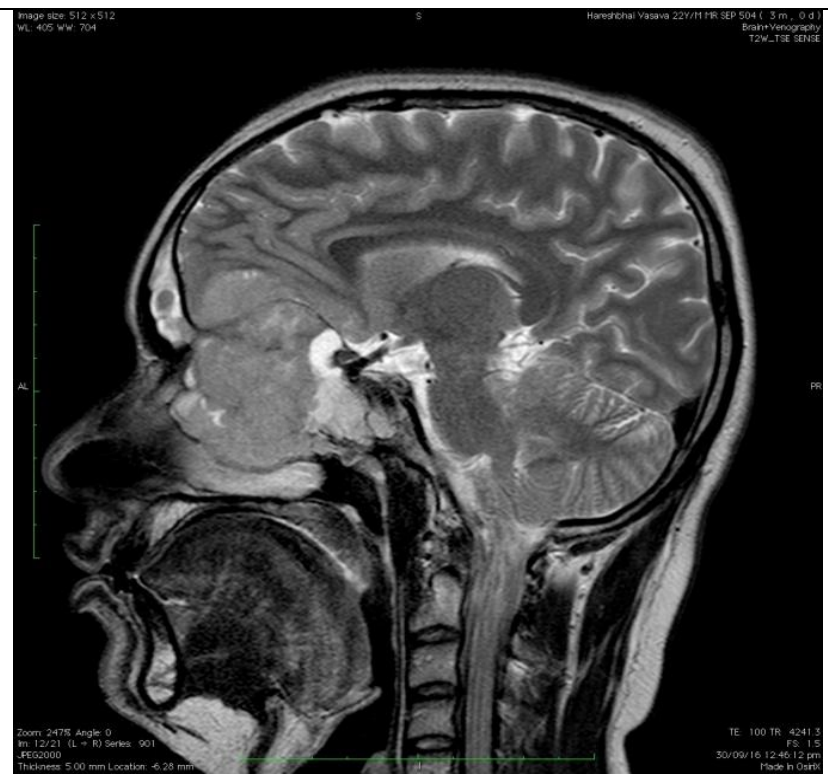

Figure 3

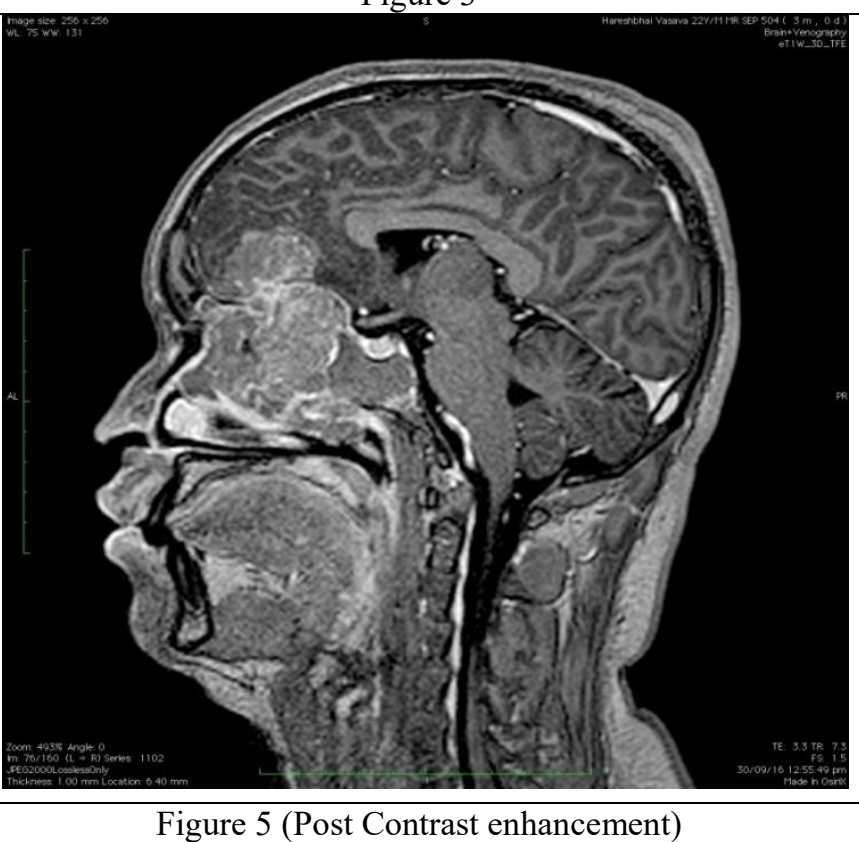

Figure 5 (Post Contrast enhancement)

Endoscopic transnasal biopsy was taken and send for histopathology department which was seen of vascular proliferation with small round cells focally forming Homer wright rosette, area of necrosis and absent to low mitotic figures were seen. Overall features were suggestive of Esthesioneuroblastoma. Patient was operated and endo-nasal skull base tumor resection was done and then referred to higher center for radiotherapy and chemotherapy.

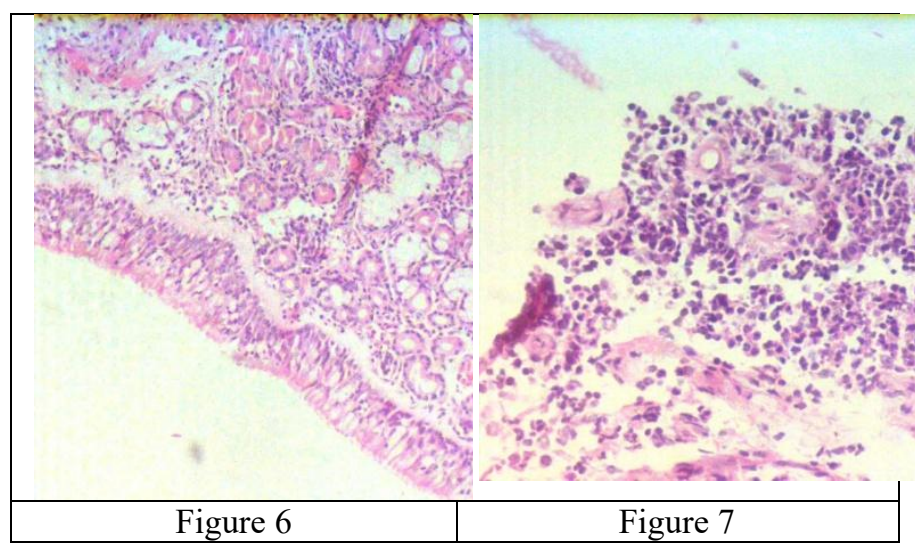

Volume 6 Issue 1, January 2017 www.ijsr.net 


\section{International Journal of Science and Research (IJSR) \\ ISSN (Online): 2319-7064}

Index Copernicus Value (2015): 78.96 | Impact Factor (2015): 6.391

\section{Discussion}

The tumor was first reported in the English literature by Schall and Lineback [4] at the Massachusetts Eye and Ear Infirmary in 1951, when they reported three cases of Primary intranasal neuroblastoma. Esthesioneuroblastoma is a rare malignant neuroectodermal nasal tumor that constitutes about $2 \%$ of all sinonasal tract tumors without any specific age, sex or racial predilection. These tumors have been designated previously as Esthesioneuroblastoma, esthesioneuroepithelioma,

esthesioneurocytoma and olfactory placode tumor. Esthesioneuroblastoma arises from olfactory neuroepithelium which extends from the superior turbinate and portion of nasal septum up to the roof of the nose [4]. It can also arise from the cells of the sphenopalatine ganglion and jacobson's organ. The olfactory neuroepithelium is somewhat unique as it can be present as low as the medial aspect of middle turbinate. The epithelium is pseudostratified and consists of bipolar neurons, sustentacular cells and basal cells.

Kadish et al. [5] were the first to propose a staging classification for Esthesioneuroblastoma. Staging was given as per Group A: limited to tumors of the nasal fossa; Group B: extension to the paranasal sinuses; and Group C: extension beyond the paranasal sinuses. Biller et al. [ㅁ] gave their staging as: T1: indicates tumor involving the nasal cavity and paranasal sinuses, excluding the sphenoid, with or without erosion of the bone of the anterior cranial fossa; T2: tumor extending into the orbit or protruding into the anterior cranial fossa; T3: tumor involving the brain that is resectable with margins; and T4: unresectable tumor. Dulguerov and Calcaterra [7] further modified the grading to: $\mathrm{T} 1$ : indicates tumor involving the nasal cavity and/or paranasal sinuses, excluding the sphenoid, sparing most superior ethmoidal cells; T2: tumor involving the nasal cavity and/or paranasal sinuses, including the sphenoid, with extension to or erosion of the cribriform plate; T3: tumor extending into the orbit or protruding into the anterior cranial fossa; and T4: tumor involving the brain.

Treatment modalities have included extra cranial surgical excision, craniofacial surgical resection, radiotherapy and chemotherapy used alone or in combination. Loubutin et al. [8] observed that leptomeningeal infiltration by Esthesioneuroblastoma carried a poor prognosis. Homzie and Elkon [9] included the presence of metastases and local extension of the tumor (e.g., ethmoidal, nasopharynx, orbital) as negative prognostic factors in their series. Resto et al. [10] found that the only predictor of survival was nodal metastases. Broich et al. [1] reviewed the literature and found a $72.5 \%$ 5-year survival rate in patients treated with combined therapies compared with $62.5 \%$ with surgery alone and $53.8 \%$ with Radiotherapy alone. Dulguerov and Calcaterra [7] observed in their study that $92 \%$ of patients treated with complete gross resection of the tumor plus Radiotherapy remained recurrence free, as opposed to $40 \%$ with Radiotherapy alone and $14 \%$ with surgery alone.

\section{Conclusion}

Esthesioneuroblastoma has a propensity for rapid metastasis. So in every patient presenting with nasal obstruction and epistaxis and intracranial signs and symptoms in the 2 nd to 4th decade should be evaluated for Esthesioneuroblastoma. Because of its close resemblance to round cell tumors like lymphoma, rhabdomyosarcoma, undifferentiated carcinoma and malignant melanoma special immunohistochemical stains has become very essential for proper and accurate diagnosis.

\section{References}

[1] Broich G, Pagliari A, Ottaviani F Esthesioneuroblastoma: a general review of the cases published since the discovery of the tumour in 1924. Anticancer Res. 1997;17(4A):2683-2706.

[2] Berger L, Luc R. Esthésioneuroépithéliome olfactif. Bull Assoc Fr Etud Cancer. 1924;3:410-421.

[3] Elkon D, Hightower SI, Lim ML, et al. Esthesioneuroblastoma. Cancer. 1979;44:1087-1094. doi: $\quad 10.1002 / 1097-0142(197909) 44: 3<1087:: A I D$ CNCR2820440343>3.0.CO;2-A.

[4] Schall LA, Lineback M. Primary intranasal neuroblastoma. Annals of otology, Rhinology and Laryngology. 1951;60: 221-229.

[5] Kadish S, Goodman M, Wang CC. Olfactory neuroblastoma: a clinical analysis of 17 cases. Cancer. 1976;37:1571-1576. doi: 0142(197603)37:3<1571::AIDCNCR2820370347>3.0.CO;2-L.

[6] Biller HF, Lawson W, Sachdev VP, Som P. Esthesioneuroblastoma: surgical treatment without radiation. Laryngoscope. 1990;100:1199-1201. doi: 10.1288/00005537-199011000-00013.

[7] Dulguerov P, Calcaterra T. Esthesioneuroblastoma: the UCLA experience 1970-1990. Laryngoscope. 1992;102:843-849. doi: 10.1288/00005537-19920800000001

[8] Loubutin JP, Maugard-Loubutin C, Fumoleau P. Leptomeningeal infiltration in esthesioneuroblastoma: report of two cases with poor prognosis. Eur Neurol. 1994;34:236-238. doi: 10.1159/000117046.

[9] Homzie MJ, Elkon D. Olfactory esthesioneuroblastoma: variables predictive of tumor control and recurrence. Cancer. 1980;46:2509-2513. doi: 10.1002/10970142(19801201)46:11<2509::AIDCNCR2820461132>3.0.CO;2-Z.

[10]Resto VA, Eisele DW, Forastiere A, et al. Esthesioneuroblastoma: the Johns Hopkins experience. Head Neck. 2000;22:550-558. doi: 10.1002/10970347(200009)22:6<550::AID-HED2>3.0.CO;2-0. 